\title{
Chinese herbal medicine
} for constipation: zheng-based associations among herbs, formulae, proprietary medicines,
and herb-drug interactions

Linda L. D. Zhong ${ }^{1,2 \dagger}$, Guang Zheng ${ }^{1,5 \dagger}{ }^{4}$ Li Da Ge ${ }^{3}$, Cheng Yuan Lin ${ }^{1,2}$, Tao Huang ${ }^{1,2}$, Ling Zhao ${ }^{1,2}$, Cheng Lu ${ }^{1,4}$, Ai Ping Lu $u^{1,2,4}$ and Zhao Xiang Bian ${ }^{1,2^{*}}$

\begin{abstract}
Background: As current symptomatic treatments of constipation are still unsatisfactory, an increasing number of patients seek help from Chinese medicine (CM), particularly Chinese herbal medicine (CHM). This study aimed to review the most frequently used CHM herbs and formulae, proprietary $\mathrm{CHMs}$, and herb-drug interactions for functional constipation using zheng (syndrome)-based differentiation, and to determine the current practice of zhengbased CHM treatments for functional constipation.

Methods: We developed a search strategy to include all the related clinical studies of CHM for constipation and set inclusion and exclusion criteria as studies on subjects with constipation of all ages and both sexes, using objective measures from laboratory or imaging techniques. The interventions included single herbs, CM classical formulae, CM new formulae, and Chinese herb-derived products and combination products. The clinical study types included were quasi- or randomized controlled trials, observational clinical studies, case series or case reports, and other types of appropriate research methods. The data concerning study design, sample size, mode of recruitment, sampling and diagnostic procedure, inclusion and exclusion criteria, and participants' characteristics (including age, sex, and duration of constipation). CM patterns, CM treatment principles, treatment regimen, and CM treatment outcomes were recorded.

Results: A total of 29,832 relevant records were found, of which 8541 were duplicate records and 20,639 were excluded for reasons of irrelevance. The full text of 965 articles was retrieved for detailed assessment, following which 480 articles were excluded for various reasons. From the included articles, we retrieved 190 different CM zheng diagnoses from 485 individual studies. The most common zheng was dual deficiency of qi and blood ( $N=48$ ), which was diagnosed in 948 out of 15,740 subjects. The most frequently used classical formula was Ma-Zi-Ren-Wan (MZRW) $(N=75)$ and the most frequently used proprietary CHM was Run-Chang-Wan $(N=87)$. The most frequently used combined medication was Da Huang with sodium bicarbonate tablets (frequency across all studies, $\mathrm{n}=23$ ), followed by Fan Xie Ye with lactulose oral solution $(n=8)$, Ma-Ren-Ruan-Jiao-Nang with lactulose oral solution $(n=6)$ and LiuWei-An-Xiao-Jiao-Nang ( $\mathrm{n}=6$ ) with mosapride citrate tablets.
\end{abstract}

\footnotetext{
*Correspondence: bzxiang@hkbu.edu.hk

†Linda LD Zhong and Guang Zheng contributed equally to this work and should be considered co-first authors

${ }^{1}$ School of Chinese Medicine, Hong Kong Baptist University, 7 Baptist

University Road, Kowloon Tong, Hong Kong, China

Full list of author information is available at the end of the article
} 
Conclusion: This study examined the use of $\mathrm{CHM}$ for constipation and summarized the herbs, formulae, proprietary medicines, and herb-drug interactions application. These data indicated there were limited information about herb-drug interactions and adverse effects of $\mathrm{CHM}$ and further randomized controlled trials with strict design are necessary.

\section{Background}

Constipation is a common functional bowel disorder that affects many people; $14.7 \%$ of the United States population [1], and $15.6 \%$ of the adult population in Hong Kong [2] experienced this problem in a large sampled cross-sectional survey published in 2014. Treatments for constipation usually include fiber supplements, osmotic and stimulant laxatives, stool softeners, and sometimes enemas for refractory constipation [3]. As current symptomatic treatments produce unsatisfactory responses [4], many patients seek help from Chinese medicine $(\mathrm{CM})$, particularly Chinese herbal medicine (CHM).

Many $\mathrm{CM}$ interventions have been used to treat constipation. A recent review [5] listed the current clinical research findings from $\mathrm{CM}$ interventions for functional constipation. However, there have been no analysis of the benefits of individual interventions (or individual types of interventions) or of the qualities of individual study designs. Our research team conducted a systematic review of $\mathrm{CHM}$ for functional constipation [6] and showed that CHM or CHM combination therapy was more effective than some single conventional medicines [6]. However, these findings did not accurately reflect all clinical practice, as most clinical research on constipation has involved observational studies or case series, and clinical practice has mostly been limited to personal experiences and based on CM theory and zheng (syndrome) differentiation [7-9].

We aimed to investigate CHM applications for constipation based on zheng differentiation, especially the use of single herbs, CM formulae, proprietary CHMs, and herb-drug interactions. Therefore, we systematically reviewed all the available data from current databases, including clinical trials, clinical observational studies, case series, case reports, and case control studies. Because we examined large data sets from both conventional Western and CM literature, we used a data slicing algorithm for text mining [10].

This study aimed to review the most frequently used $\mathrm{CHM}$ herbs and formulae, proprietary CHMs, and herb-drug interactions for functional constipation using zheng-based differentiation, and to determine the current practice of zheng-based CHM treatments for functional constipation.

\section{Methods \\ Literature search}

The review was performed in accordance with the Preferred Reporting Items for Systematic Reviews and MetaAnalyses (PRISMA) guidelines. We used the following databases to search the conventional medicine literature: PubMed, Ovid, Evidence-Based Medicine Reviews (EBMR), and Embase. The following databases were used to search the traditional CM literature: SinoMed, Chinese National Knowledge Infrastructure (CNKI), Chinese biomedical literature (CBM) CD, and China Journals Fulltext Database. From the electronic database records and bibliographic references, we identified relevant primary sources and secondary sources (such as textbooks, review articles, and meta-analyses) as follows. We selected all EBM reviews, including Cochrane DSR, ACP Journal Club, DARE, CCTR, CMR, HTA, and NHSEED from inception to April 2014; EMBASE from 1980 to April 2014; EMBASE Classic from 1947 to 1979; PubMed from inception to April 2014; Ovid MEDLINE(R) from 1950 to April 2014; Ovid OLDMEDLINE(R) from 1948 to 1965; SinoMed from 1978 to April 2014; China Journals Full-text Database from 1994 to April 2014 and CBM disc from 1979 to April 2014. The search strategy was (1) (constipation) OR (chronic constipation) OR (functional constipation); (2) (herb*) OR (herbal medicine) OR (traditional Chinese medicine) OR (Chinese medicine) OR (Complementary medicine) OR (Naturopathy); (3) (case*) OR (clinical observation*) OR (clinical trial) OR (clinical study); (1) AND (2) AND (3) ("was used for truncation).

\section{Study selection}

We included interventions using single herbs, CM classical formulae, CM new formulae, and Chinese herb-derived products and combination products. The clinical study types included were quasi- or randomized controlled trials, observational clinical studies, case series or case reports, and other types of appropriate research methods. We included studies on subjects with constipation of all ages and both sexes, studies using objective measures from laboratory or imaging techniques, and studies using measurement from nursing staff, patients, or other informants.

\section{Data extraction}

Two authors (LLDZ and GZ) independently searched the databases and selected relevant publications. If the 
two authors disagreed about a study's eligibility, they would check the study against the selection criteria, discuss its eligibility, and make a further decision (ZXB). One author (LLDZ) extracted the data and the other (GZ) checked the extracted data. For each study, the following information was extracted: study design, sample size, mode of recruitment, sampling and diagnostic procedure, inclusion and exclusion criteria, and participants' characteristics (including age, sex, and duration of constipation). CM patterns, CM treatment principles, treatment regimen, and $\mathrm{CM}$ treatment outcomes were recorded.

\section{Quality assessment}

The methodological quality of relevant studies was assessed using the Jadad scale (Additional file 1; [11]). The Jadad scale evaluates a study in terms of the description of randomization, blinding, and dropouts. The scale ranges from 1 to 5 ; randomized controlled trials with a score between 3 and 5 are regarded as better quality trials. Points were awarded if the study was described as randomized (1 point), had an appropriate randomization method (1 point), was described as double-blind (1 point), used an appropriate blinding method (1 point), and had a description of withdrawals and dropouts (1 point) [11].

\section{Identification of herb-zheng associations}

Classification based on keyword co-occurrence was conducted on the 18,272 items of constipation literature downloaded from SinoMed [12]. We also applied a dictionary-based data slicing algorithm constructed on the principle of keyword co-occurrence. We filtered the downloaded data using CM associated keywords, such as "Chinese herbal medicine," "Chinese patent medicine," and "CM syndrome/zheng," which were obtained from textbooks and the Internet. The keyword cooccurrence classification was a good supplement to the literature search, as it provided insights into the quantitative relationship between the individual herbs and formulae used to treat constipation. We used a wheelshaped network to indicate the association between different types of single herbs and their zheng indications [10]. The wheel-shaped network was a visualized graph that showed the frequencies and correlations among the same categories [10].

\section{Translation of terminology}

All Chinese-to-English translations were deduced primarily from the World Health Organization (WHO) Evidence-Based Complementary and Alternative Medicine International Standard Terminologies on Traditional Medicine in the Western Pacific Region [13].

\section{Results}

We accessed 29,832 records that fit the search criteria, of which 8541 were duplicate records and 20,639 were excluded for reasons of irrelevance. The full text of 965 articles was retrieved for detailed assessment; 480 of these were excluded for various reasons (Fig. 1). Of the 485 studies that fulfilled the inclusion and exclusion criteria, 289 were on CM formulae, 91 were on proprietary $\mathrm{CM}$, and 105 were on a combination of CHM and conventional treatment. The sample size of the 485 studies ranged from 35 to 250 . Among all the studies, 289 $(59.6 \%)$ were case series or reports, 125 (25.8\%) were controlled trials, and 71 (14.6\%) were randomized controlled trials. For the randomized controlled trials, the mean Jadad scores were 2.06 and their average quality was quite low (Additional file 1).

\section{$\mathrm{CM}$ zheng category and treatment criteria}

From the included articles, we retrieved 190 different CM zheng diagnoses from 485 individual studies. The most common pattern was dual deficiency of qi and blood (Qi Xue Liang Xu), which was diagnosed in 948 of the 15,740 subjects (frequency $=48$, percentage among the top 10 diagnosis $=16.8 \%$ ); this was followed by dual deficiency of qi and yin (Qi Yin Liang Xu) (subjects $=795$, frequency $=45$, percentage among the top 10 diagnosis $=15.7 \%$ ), excessive heat and qi stagnation ( $Q i$ Zhi Shi Re) (subjects $=726$, frequency $=41$, percentage among the top 10 diagnosis $=14.3 \%$ ), yang

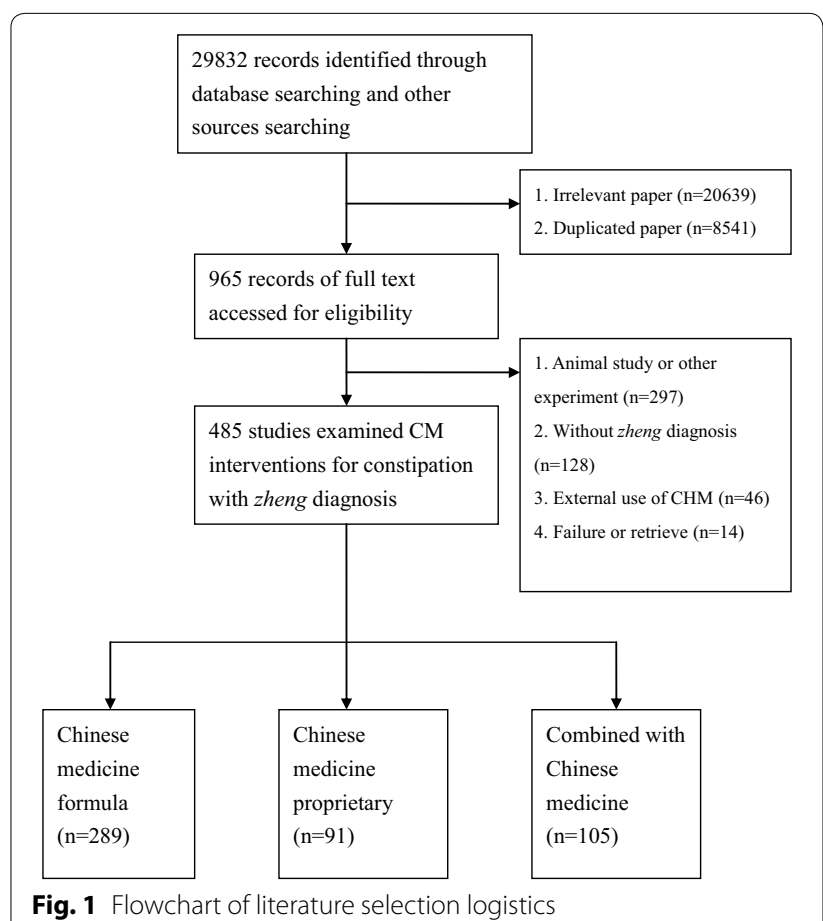


deficiency of spleen and kidney (Pi Shen Yang Xu) (subjects $=636$, frequency $=32$, percentage among the top 10 diagnosis $=11.2 \%$ ), deficiency of qi and blood (Qi Xue Liang $X u$ ) (subjects $=595$, frequency $=26$, percentage among the top 10 diagnosis $=9.1 \%$ ), cold-heat complex (Han Re Cuo Za) (subjects $=513$, frequency $=21$, percentage among the top 10 diagnosis $=7.3 \%$ ), liver depression and spleen deficiency (Gan Yu Pi Xu) (subjects $=495$, frequency $=20$, percentage among the top 10 diagnosis $=7.0 \%$, deficiency-excess complex $(X u$ Shi Jia $\mathrm{Za}$ ) (subjects $=483$, frequency $=20$, percentage among the top 10 diagnosis $=7.0 \%$ ), dual yin deficiency of liver and kidney (Gan Shen Yin Xu) (subjects $=410$, frequency $=17$, percentage among the top 10 diagnosis $=5.9 \%$ ) and intestinal dryness and yin deficiency (Yin $X u$ Chang Zao) (subjects $=223$, frequency $=16$, percentage among the top 10 diagnosis $=5.6 \%$ ). Subjects diagnosed with the top $10 \mathrm{CM}$ zheng accounted for $37 \%$ of the 15,740 subjects (Table 1 ). Table 1 lists the therapeutic principles for the CM zheng.

\section{CM herbs and their relationships}

We identified 296 herbs from 485 clinical studies and analyzed their relationships using the wheel-shaped network (Fig. 2). In this figure, red and green nodes represent different single herbal medicines. The edges represent co-occurrence frequency in clinical studies. The edge label numbers represent the number of clinical studies demonstrating a connection between two single herbal medicines. There was a high concentration of one classical Chinese herbal formula, Ma-Zi-Ren-Wan, whose composition of six herbs occupied $42.5 \%(1754 / 4127)$ of the total frequency of usage. Based on this, the green nodes represent CHMs in the formula Ma-Zi-Ren-Wan and the red nodes represent other $\mathrm{CHMs}$ used in clinical prescriptions [10]. Node size was calculated with the formula

$$
\text { Node size }=\text { LOG (node_frequency) }+ \text { Degree (node) }
$$

where node_frequency is the literature record number of the associated keyword calculated in text mining, LOG is the logarithm calculation with a base set to 10 , and Degree (node) is the number of connections/edges each node has with other nodes. The edge line width was calculated through LOG (edge_co-occurrent) where edge_cooccurrent was the number of node/keyword pairs that co-occurred in the associated literature.

Table 2 lists the top 10 most frequently used herbs and their actions. The most frequently used herbs were further categorized and analyzed to determine their combinations in classical formulae. The most frequently used classical formulae were Ma-Zi-Ren-Wan [14] and ZengYe-Tang [15].

\section{$\mathrm{CM}$ zheng-based Chinese herbal formulae}

Among the 289 studies on Chinese herbal formulae, the most frequently used formulae based on zheng diagnosis

Table 1 Top ten most commonly used CM zheng for constipation

\begin{tabular}{|c|c|c|c|c|}
\hline CM zheng & Therapeutic principle & $\begin{array}{l}\text { Number of subjects diag- } \\
\text { nosed by the diagnosis }\end{array}$ & $\begin{array}{l}\text { Number of frequency } \\
\text { among all the studies }\end{array}$ & $\begin{array}{l}\text { Percentage among the } \\
\text { total zheng (190)/top } 10 \\
\text { zheng diagnosis (\%) }\end{array}$ \\
\hline $\begin{array}{l}\text { Dual deficiency of qi and blood } \\
\text { qi-xue-liang-xu }\end{array}$ & Tonify qi and replenish blood & 948 & 48 & $16.8 / 6.2$ \\
\hline $\begin{array}{l}\text { Dual deficiency of qi and yin } \\
\text { qi-yin-liang-xu }\end{array}$ & Tonify qi and replenish yin & 795 & 45 & $15.7 / 5.9$ \\
\hline $\begin{array}{l}\text { Excessive heat and qi stagnation } \\
\text { qi-zhi-shi-re }\end{array}$ & Soothe the liver and regulate qi & 726 & 41 & $14.3 / 5.3$ \\
\hline $\begin{array}{l}\text { Yang deficiency of spleen and } \\
\text { kidney pi-shen-yang-xu }\end{array}$ & $\begin{array}{l}\text { Warm the kidney and fortify } \\
\text { the spleen }\end{array}$ & 636 & 32 & $11.2 / 4.2$ \\
\hline $\begin{array}{l}\text { Deficiency of qi and blood pi- } \\
\text { xue-kui-xu }\end{array}$ & Tonify qi and engender blood & 595 & 26 & $9.1 / 3.4$ \\
\hline $\begin{array}{l}\text { Cold-heat complex han-re- } \\
\text { cuo-za }\end{array}$ & $\begin{array}{l}\text { Treat cold with heat and heat } \\
\text { with cold }\end{array}$ & 513 & 21 & $7.3 / 2.7$ \\
\hline $\begin{array}{l}\text { Liver depression and spleen } \\
\text { deficiency gan-yu-pi-xu }\end{array}$ & $\begin{array}{l}\text { Soothe the liver and fortify the } \\
\text { spleen }\end{array}$ & 495 & 20 & $7.0 / 2.6$ \\
\hline $\begin{array}{l}\text { Deficiency-excess complex xu- } \\
\text { shi-jia-za }\end{array}$ & $\begin{array}{l}\text { Treat deficiency by tonification } \\
\text { and excess by purgation }\end{array}$ & 483 & 20 & $7.0 / 2.6$ \\
\hline $\begin{array}{l}\text { Dual yin deficiency of liver and } \\
\text { kidney gan-shen-yin-xu }\end{array}$ & $\begin{array}{l}\text { Enrich the kidney and nourish } \\
\text { the liver yin }\end{array}$ & 410 & 17 & $5.9 / 2.2$ \\
\hline $\begin{array}{l}\text { Intestinal dryness and yin defi- } \\
\text { ciency yin-xu-chang-zao }\end{array}$ & $\begin{array}{l}\text { Replenish yin and moisten } \\
\text { dryness }\end{array}$ & 223 & 16 & $5.6 / 2.1$ \\
\hline
\end{tabular}



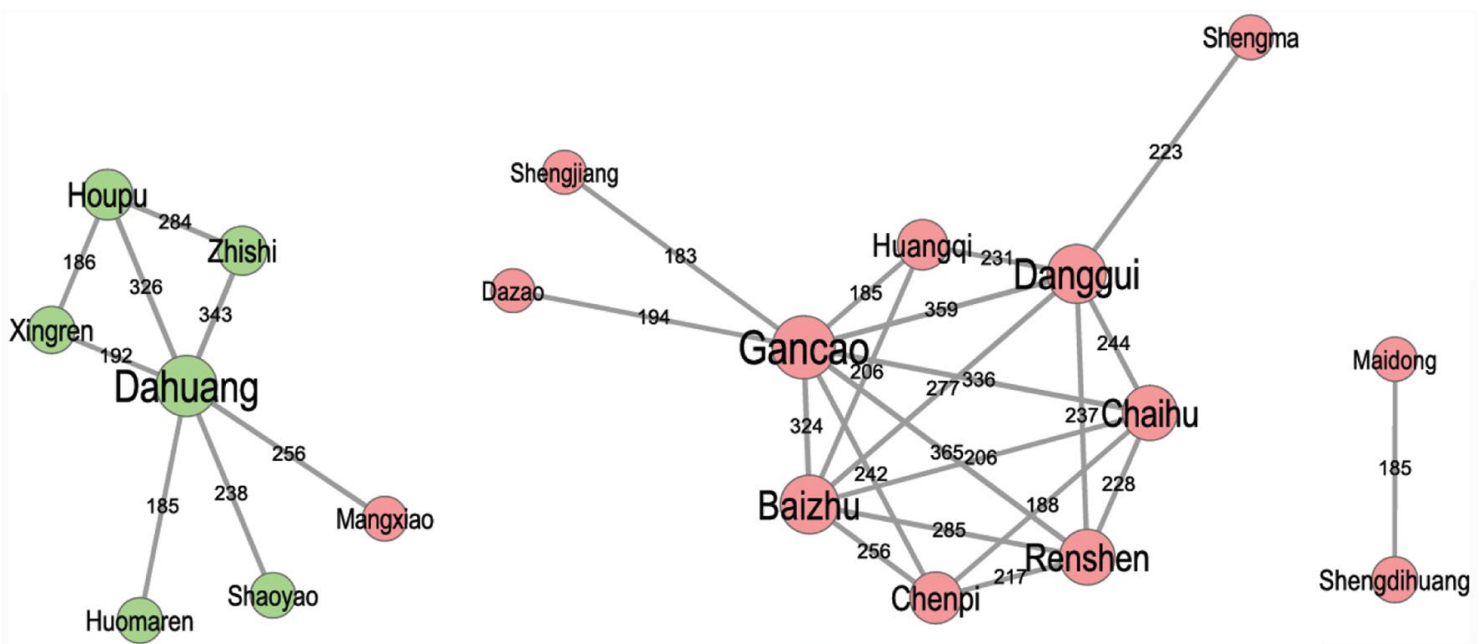

Fig. 2 Network relationship of Chinese herbal medicine in the treatment of constipation. Red and green nodes represent different single herbal medicines. The edges represent co-occurrence frequency in clinical studies. The edge label numbers represent the number of clinical studies demonstrating a connection between two single herbal medicines

were $\mathrm{Ma}$-Zi-Ren-Wan and its modifications (frequency among all the studies, $\mathrm{n}=75$, percentage among the top 10 formulae, $33.07 \%)$. This was followed by Bu-ZhongYi-Qi-Tang ( $\mathrm{n}=56,22.58 \%)$, Ji-Chuan-Jian $(\mathrm{n}=51$, $20.56 \%)$, Zeng-Ye-Tang ( $\mathrm{n}=40,13.84 \%$ ), and Ba-ZhenTang $(\mathrm{n}=26,10.48 \%)$. The five most frequently used CM zheng-based Chinese herbal formulae and their indications are summarized in Table 3.

\section{Proprietary CHMs}

After the classical herbal decoctions, the next most frequently used clinical treatments for constipation were proprietary CHMs, because of their standard quality control and more convenient administration. We analyzed the most commonly used proprietary CHMs and their dosage (Table 4). The manufacturers of the proprietary CHMs are also shown, to indicate the quality and composition of the medicines. The most commonly used proprietary CHM was Run-Chang-Wan (frequency, $\mathrm{n}=87$ ), followed by Ma-Ren-Ruan-Jiao-Nang ( $=62)$, Ma-RenRun-Chang-Wan ( $\mathrm{n}=52)$, Liu-Wei-An-Xiao-Jiao-Nang $(\mathrm{n}=50)$, Fu-Fang-Lu-Hui-Jiao-Nang $(\mathrm{n}=35), \mathrm{Si}$-Ni-San $(\mathrm{n}=32)$, Liu-Wei-Neng-Xiao-Jiao-Nang $(\mathrm{n}=27)$, and Bu-Zhong-Yi-Qi-Wan $(\mathrm{n}=17)$.

\section{$\mathrm{CM}$ combined with Western medicine and adverse effects}

Few clinical studies reported the combined use of $\mathrm{CM}$ and Western medicine for constipation. Table 5 summarized the herb-drug interactions identified. Although most studies did not mention the adverse effects associated with combined administration of herbs and drugs, or proprietary CHMs and drugs, there were 43 reported trials of the integrative use of single herbs or proprietary CHMs. Among these studies, the most frequent adjunctive use was Da Huang (Radix et Rhizoma Rhei) with sodium bicarbonate tablets $(\mathrm{n}=23)$, followed by Fan Xie Ye (Folium Sennae) with lactulose oral solution $(\mathrm{n}=8)$, Ma-Ren-Ruan-Jiao-Nang with lactulose oral solution $(\mathrm{n}=6)$ and Liu-Wei-An-Xiao-Jiao-Nang with mosapride citrate tablets $(\mathrm{n}=6)$.

\section{Discussion}

To our knowledge, this is the first study to examine the use of single herbs, classical CM formulae, proprietary CHMs, and the combined use of CM and Western medicine (and its adverse effects) for constipation. The classification of single herbs and CM formulae was generally based on the CM diagnostic zheng system. As we pointed out in our commentary paper, zheng diagnosis is a critical stage of CM treatment; it is the basis of CM's effectiveness and the main feature that distinguishes it from Western medicine [16]. In this review, we focused on zheng diagnosis, in accord with current clinical CM practice. Although we identified 190 different CM zheng diagnoses, only $57.9 \%(281 / 485)$ of studies used the diagnosis system of zheng differentiation. The most commonly diagnosed zheng for constipation was dual deficiency of qi and blood (16.8 \%) followed by dual deficiency of qi and yin (15.7\%) and excessive heat and qi stagnation (14.3\%). As Table 1 showed, among the top $10 \mathrm{CM}$ zheng, five belonged to deficiency zheng and the others could be categorized as a combination of deficiency and sufficiency or sufficiency syndrome. These results are consistent with those of our previous study [16] and with other research 


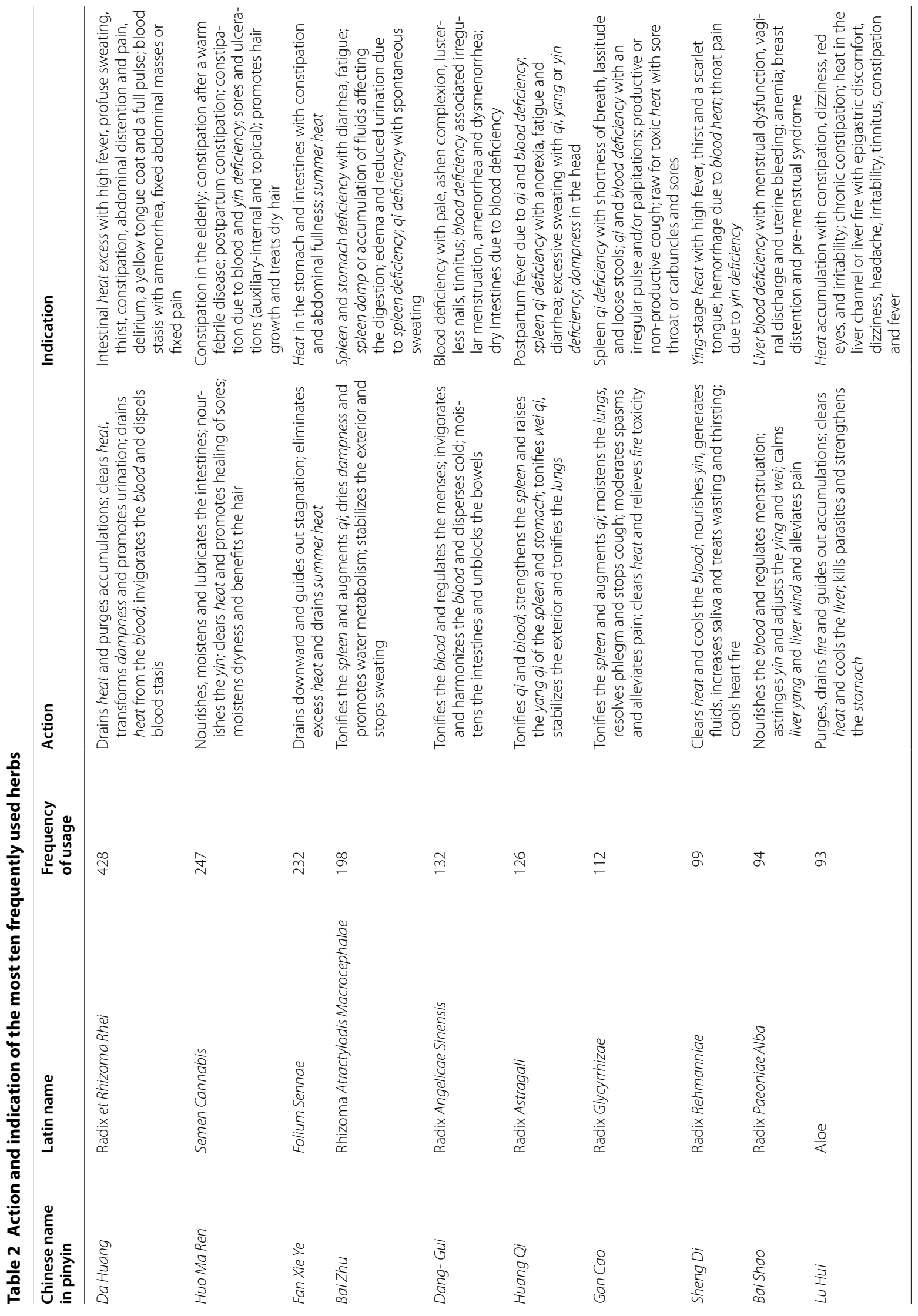


Table 3 Summary of top five most frequently used Chinese herbal formulae based on zheng diagnosis

\begin{tabular}{|c|c|c|c|c|}
\hline $\begin{array}{l}\text { Chinese name } \\
\text { in pinyin }\end{array}$ & $\begin{array}{l}\text { Composition } \\
\text { in pinyin }\end{array}$ & CM zheng & $\begin{array}{l}\text { Number of frequency } \\
\text { among all the studies }\end{array}$ & $\begin{array}{l}\text { Actions in Chinese } \\
\text { medicine }\end{array}$ \\
\hline Ma-Zi-Ren-Wan & $\begin{array}{l}\text { Huo MaRen } \\
\text { Xing Ren } \\
\text { BaiShao } \\
\text { ZhiShi } \\
\text { HouPu } \\
\text { DaHuang }\end{array}$ & Excessive qi and heat & 75 & $\begin{array}{l}\text { Invigorates Blood } \\
\text { Dispels Blood Stasis } \\
\text { Moves qi } \\
\text { Lubricates the intestines } \\
\text { Moves the bowels } \\
\text { Purges heat } \\
\text { Alleviates pain }\end{array}$ \\
\hline Bu-Zhong-Yi-Qi-Tang & $\begin{array}{l}\text { Huang Qi } \\
\text { Ren Shen } \\
\text { Bai Zhu } \\
\text { ZhiGan Cao } \\
\text { Dang Gui } \\
\text { Chen Pi } \\
\text { Shen Ma } \\
\text { Chai Hu }\end{array}$ & $\begin{array}{l}\text { Qideficiency of spleen and } \\
\text { stomach/Sunken middle ai }\end{array}$ & 56 & $\begin{array}{l}\text { Tonifies middle jiao qi } \\
\text { Benefits qi } \\
\text { Regulates qi } \\
\text { Raises sunken yang } \\
\text { Lifts prolapsed organs }\end{array}$ \\
\hline Ji-Chuan-Jian & $\begin{array}{l}\text { Dang Gui } \\
\text { Niu Xi } \\
\text { Rou Cong Rong } \\
\text { ZeXie } \\
\text { Shen Ma } \\
\text { Zhi Qiao }\end{array}$ & $\begin{array}{l}\text { Yang deficiency of spleen and } \\
\text { kidney }\end{array}$ & 51 & $\begin{array}{l}\text { Warms up the kidney } \\
\text { Replenishes vital essence } \\
\text { Lubricates the intestines } \\
\text { Induces defecation }\end{array}$ \\
\hline Zeng-Ye-Tang & $\begin{array}{l}\text { Xuan Shen } \\
\text { Mai Dong } \\
\text { Sheng Di }\end{array}$ & Fluid-humor deficiency & 40 & $\begin{array}{l}\text { Generates Fluids } \\
\text { Moistens dryness } \\
\text { Unblocks the bowels } \\
\text { Nourishes yin } \\
\text { Clears heat }\end{array}$ \\
\hline Ba-Zhen-Tang & $\begin{array}{l}\text { Ren Shen } \\
\text { Bai Zhu } \\
\text { FuLing } \\
\text { ZhiGan Cao } \\
\text { Shu Di } \\
\text { BaiShao } \\
\text { Chuan Xiong } \\
\text { Dang Gui }\end{array}$ & Dual deficiency of qi and blood & 26 & $\begin{array}{l}\text { Nourishes qi } \\
\text { Benefits blood }\end{array}$ \\
\hline
\end{tabular}

on syndrome distribution among constipation patients $[8,17]$, which indicated that almost half of patients, especially older individuals and postpartum women, had deficiency syndromes $[18,19]$.

Of the 10 most frequently used herbs, the top three were traditional purgatives; the other herbs were tonifying and replenishing medicines, except Lu Hui (Aloe vera) $[20,21]$. It is interesting that the top five CM zheng were deficiency zheng; this seemed inconsistent with the fact that the five most frequently used single herbs were purgatives. This was mainly because only $50.26 \%$ of studies used CM zheng differentiation, and purgatives are mostly used for general constipation in the absence of any CM zheng diagnosis. Table 3 shows that the most commonly used Chinese herbal formula was Ma-Zi-Ren-Wan, which suggested that it formed the basis of the most commonly prescribed formulae for constipation according to both $\mathrm{CM}$ syndrome differentiation and Western medicine diagnosis.

Many studies of Chinese herbal formulae or proprietary CHM did not provide standard or complete criteria for syndrome diagnosis. The lack of detail and consistency in diagnosis makes these studies difficult to replicate and their findings difficult to compare with other results [22]. Most studies provided only the main composition of the formulae without any indication of dosage or quality control standards (Table 4). Although proprietary CHMs are rapidly gaining attention in the West as sources of new drugs, dietary supplements, and functional foods, the lack of consistent manufacturing processes, quality standards, scientific evidence, and validation of efficacy and safety impede worldwide acceptance of CHM [23].

Currently, herb-drug interactions are of growing concern as a clinical safety issue to clinicians and researchers [24, 25]. Proprietary CHMs are prescribed by Western medical doctors who may not fully understand the indications and actions of these medicines [26]. Although herbal medicines are natural, they are not always safe [27]. Table 5 showed the concomitant use and the adverse effects of herb-drug combinations or proprietary CHMdrug combinations based on the limited literature. These limited data showed that the incidence of adverse effects 
Zhong et al. Chin Med (2016) 11:28

Page 8 of 11

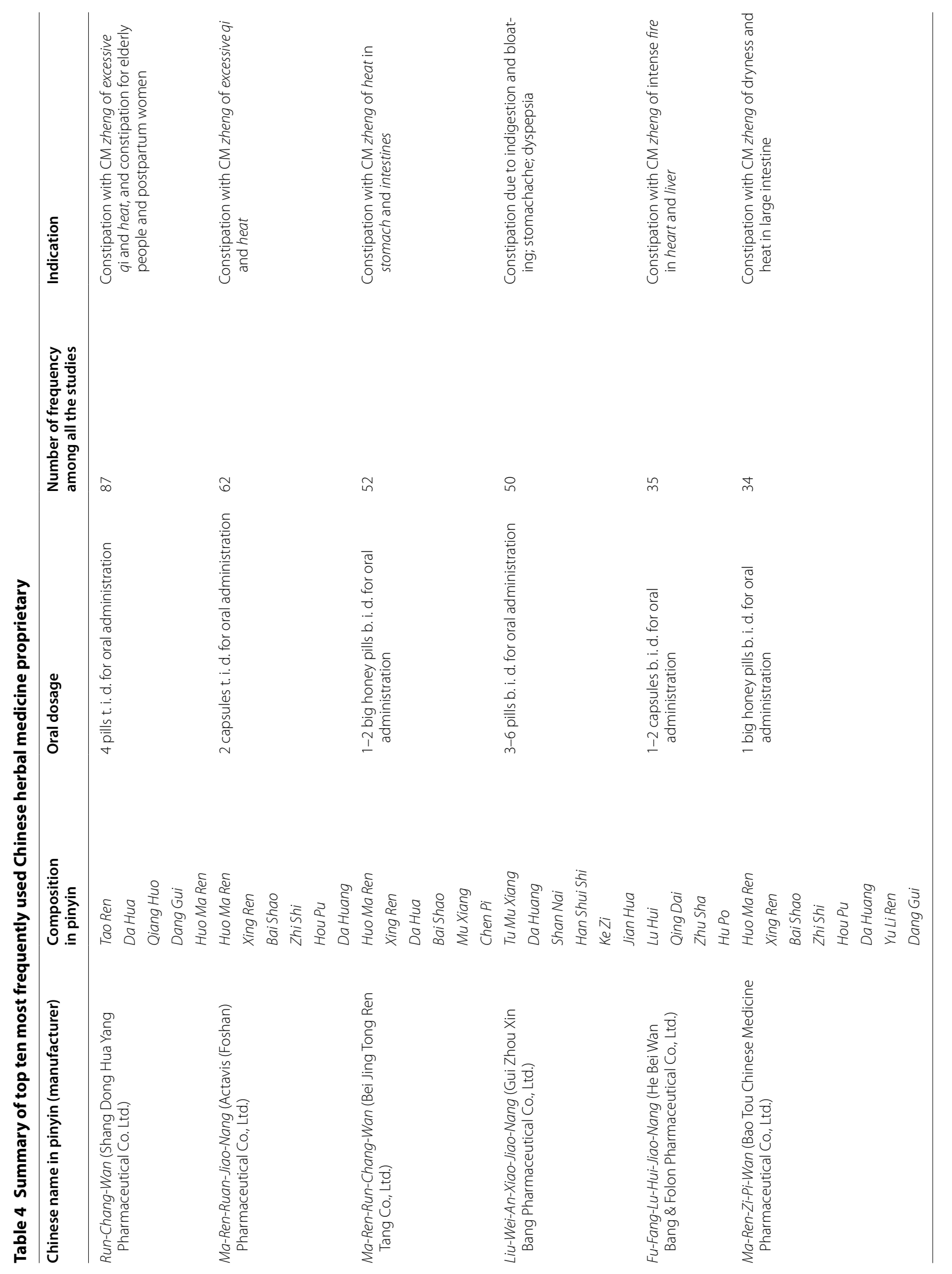




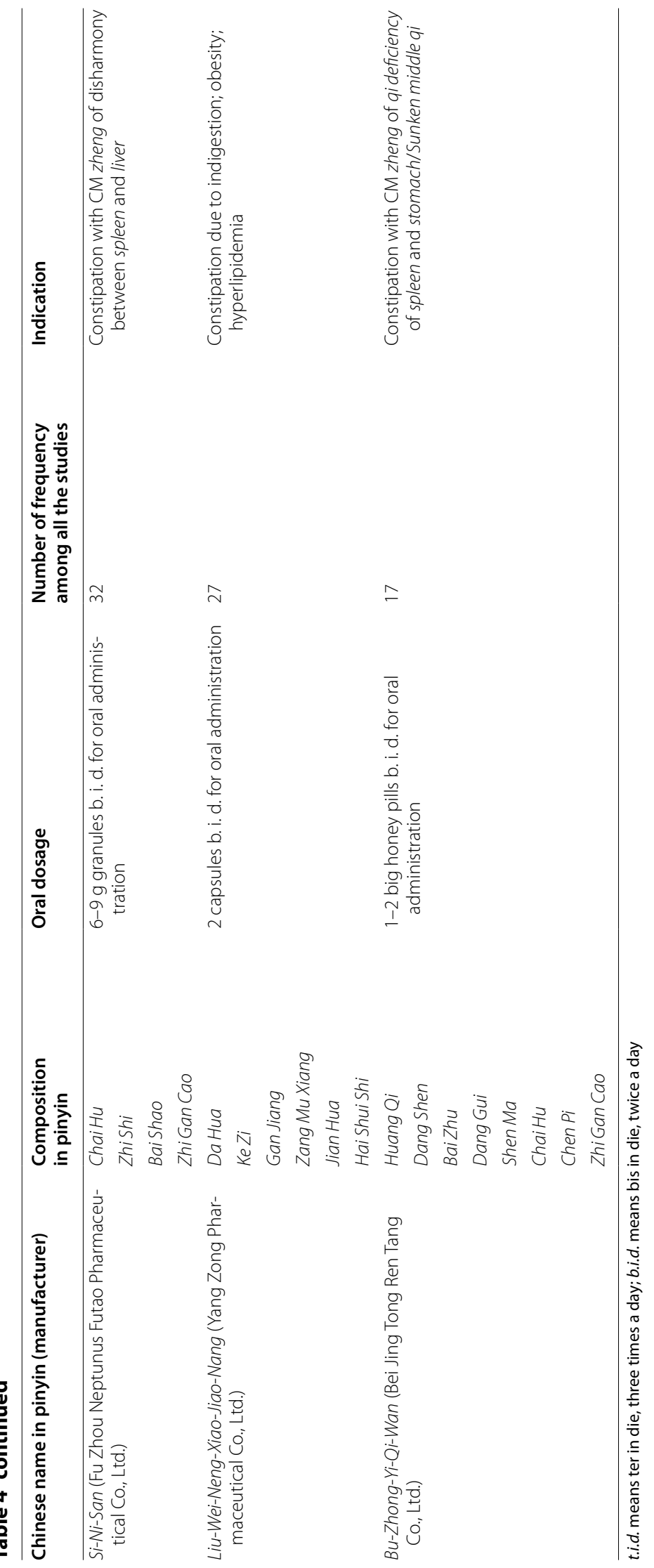


Table 5 Summary of combination of CHM and Western medicine and the reported adverse effects

\begin{tabular}{|c|c|c|c|}
\hline & $\begin{array}{l}\text { Combined used Western } \\
\text { medicine }\end{array}$ & $\begin{array}{l}\text { Frequency of } \\
\text { reported in all the trials }(n>5)\end{array}$ & Adverse effect $(\mathrm{N}=$, percentage, $\%)$ \\
\hline \multicolumn{4}{|l|}{ Single herb } \\
\hline \multirow[t]{4}{*}{ DaHuang } & Sodium bicarbonate tablets & 23 & $\begin{array}{l}\text { Symptoms of the gastrointestinal tract } \\
\qquad(\mathrm{N}=4,17.3 \%)\end{array}$ \\
\hline & & & Insomnia $(N=1,4.3 \%)$ \\
\hline & & & Skin rash $(\mathrm{N}=1,4.3 \%)$ \\
\hline & & & Headache $(\mathrm{N}=1,4.3 \%)$ \\
\hline \multirow[t]{2}{*}{ Fan Xie Ye } & Lactulose oral solution & 8 & $\begin{array}{l}\text { Symptoms of the gastrointestinal tract } \\
\qquad(\mathrm{N}=2,25 \%)\end{array}$ \\
\hline & & & Dizzy and anorexia $(\mathrm{N}=1,12.5 \%)$ \\
\hline \multicolumn{4}{|l|}{ CHM Proprietary } \\
\hline \multirow[t]{2}{*}{ Ma-Ren-Ruan-Jiao-Nang } & Lactulose oral solution & 6 & $\begin{array}{l}\text { Symptoms of the gastrointestinal tract } \\
\qquad(\mathrm{N}=2,33.3 \%)\end{array}$ \\
\hline & & & Headache $(N=1,16.7 \%)$ \\
\hline $\begin{array}{l}\text { Liu-Wei-An-Xiao-Jiao- } \\
\quad \text { Nang }\end{array}$ & Mosapride citrate tablets & 6 & $\begin{array}{l}\text { Symptoms of the gastrointestinal tract } \\
(\mathrm{N}=3,50 \%)\end{array}$ \\
\hline
\end{tabular}

was not as low as we expected, ranging from 4.3 to $50 \%$, although most adverse effects were symptoms of the gastrointestinal tract.

A limitation of this study was that the data were drawn from clinical studies that used several different types of design: case reports, cohort studies, and quasi- or randomized controlled trials. The quality of these studies varied and therefore it is difficult to compare them quantitatively. In addition, most studies did not provide sufficient detail regarding inclusion criteria of diseases and syndromes, quality control procedures for single herbs or proprietary CHMs, or withdrawal rates and reasons. Therefore, the analysis of the data derived from this study is limited and should be treated with caution.

\section{Conclusion}

This review examined the use of CHM for constipation and summarized the most frequently used Chinese single herbs, the 10 most frequently used CHM formulae and proprietary $\mathrm{CHMs}$, and the combined use of CHM and Western medicine treatments and their reported adverse effects.

\section{Additional file}

Additional file 1. RCT Jadad scores.

\section{Abbreviations}

CHM: Chinese herbal medicine; CM: Chinese medicine; MZRW: Ma-Zi-RenWan; PRISMA: Preferred Reporting Items for Systematic Reviews and MetaAnalyses; EBMR: Evidence-Based Medicine Reviews; CNKI: Chinese National Knowledge Infrastructure; CBM: Chinese biomedical literature.

\section{Authors' contributions}

ZXB designed the study. LDG and CYL conducted text mining. TH and LZ retrieved the herbs and herb-drug interaction data. LLDZ and GZ searched the literature and wrote the manuscript. LDG, CYL, TH, LZ, LLDZ, GZ, CL, and APL revised the manuscript. All authors read and approved the final manuscript.

\section{Author details}

${ }^{1}$ School of Chinese Medicine, Hong Kong Baptist University, 7 Baptist University Road, Kowloon Tong, Hong Kong, China. ${ }^{2}$ Hong Kong Chinese Medicine Study Centre, Hong Kong Baptist University, Hong Kong SAR, China. ${ }^{3}$ Department of Surgery, The First People's Hospital of Xiaoshan District, Hangzhou, China. ${ }^{4}$ Institute of Basic Research in Clinical Medicine, China Academy of Traditional Chinese Medicine, Beijing, China. ${ }^{5}$ School of Information Science and Engineering, Lanzhou University, Lanzhou, China.

\section{Acknowledgements}

We thank Health and Health Services Research Fund (Project No. 09101501), Hong Kong SAR, and Natural Science Foundation of China Project (NSFC81173363) for financially support this research. The funding agencies have no role in the design and execution of this project. They will not be involved to the analysis and interpretation of data, or make decision to submit the results.

\section{Competing interests}

The authors declare that they have no competing interests.

Received: 30 April 2015 Accepted: 27 May 2016

Published online: 23 June 2016

\section{References}

1. Mugie SM, Benninga MA, Di Lorenzo C. Epidemiology of constipation in children and adults: a systematic review. Best Pract Res Clin Gastroenterol. 2011;25(1):3-18.

2. Huang R, Ho SY, Lo WS, Lam TH. Physical activity and constipation in Hong Kong adolescents. PLoS ONE. 2014;9(2):e90193.

3. Pasanen ME. Evaluation and treatment of colonic symptoms. Med Clin North Am. 2014;98(3):529-47.

4. McCarberg BH. Overview and treatment of opioid-induced constipation. Postgrad Med. 2013;125(4):7-17. 
5. Lin LW, Fu YT, Dunning T, Zhang AL, Ho TH, Duke M, Lo SK. Efficacy of traditional Chinese medicine for the management of constipation: a systematic review. J Altern Complement Med. 2009;15(12):1335-46.

6. Cheng CW, Bian ZX, Wu TX. Systematic review of Chinese herbal medicine for functional constipation. WJG. 2009;15(39):4886-95.

7. Suo T, Gu X, Andersson R, Ma H, Zhang W, Deng W, Zhang B, Cai D, Qin X. Oral traditional Chinese medication for adhesive small bowel obstruction. Cochrane Database Syst Rev. 2012;5:CD008836.

8. Chen $C M$, Lin LZ, Zhang EX. Standardized treatment of chinese medicine decoction for cancer pain patients with opioid-induced constipation: A multi-center prospective randomized controlled study. Chin J Integr Med. 2014;20(7):496-502

9. Yao YB, Cao YQ, Guo XT, Yi J, Liang HT, Wang C, Lu JG. Biofeedback therapy combined with traditional Chinese medicine prescription improves the symptoms, surface myoelectricity, and anal canal pressure of the patients with spleen deficiency constipation. eCAM. 2013;2013:830714.

10. Zheng G, Jiang M, He X, Zhao J, Guo H, Chen G, Zha Q, Lu A. Discrete derivative: a data slicing algorithm for exploration of sharing biological networks between rheumatoid arthritis and coronary heart disease. BioData Min. 2011:4:18.

11. Moher D, Jadad AR, Tugwell P. Assessing the quality of randomized controlled trials. Current issues and future directions. Int J Technol Assess Health Care. 1996;12(2):195-208,

12. Sinomed database: http://www.sinomed.ac.cn/. Accessed 16 May 2014.

13. WHO Regional Office for the Western Pacific. WHO International Standard Terminologies on Traditional Medicine in the Western Pacific Region; 2007.

14. Zhang S. Examples for clinical use of ma zi ren wan. J Tradit Chin Med 2002;22(3):216-7.

15. Zeng ZC, Tang ZY, Fan J, Zhou J, Qin LX, Ye SL, Sun HC, Wang BL, Li D, Wang JH, Zeng MS, Guo W, Tan YS. Consideration of the role of radiotherapy for unresectable intrahepatic cholangiocarcinoma: a retrospective analysis of 75 patients. Cancer J. 2006;12(2):113-22.
16. Bian ZX, Xu H, Lu AP, Lee MS, Cheung H. Insights of Chinese medicine syndrome study: from current status to future prospects. Chin I Integr Med. 2014;20(5):326-31.

17. Cheng CW, Kwok AO, Bian ZX, Tse DM. The quintessence of traditional Chinese medicine: syndrome and its distribution among advanced cancer patients with constipation. eCAM. 2012;2012:739642.

18. Ren Z, Wu QM, Li DD, Liu WA, Li XR, Lin XM. Post-stroke constipation treated with acupuncture therapy of regulating qi circulation of fu-organ. Zhongguo zhen jiu. 2013;33(10):893-6.

19. Cherniack EP. Use of complementary and alternative medicine to treat constipation in the elderly. Geriatr Gerontol Int. 2013;13(3):533-8.

20. Wang J, Huang JH, Cheng YF, Yang GM. Banana resistant starch and its effects on constipation model mice. J Med Food. 2014;17(8):902-7.

21. Hou ML, Chang LW, Lin CH, Lin LC, Tsai TH. Determination of bioactive components in Chinese herbal formulae and pharmacokinetics of rhein in rats by UPLC-MS/MS. Molecules. 2014;19(4):4058-75.

22. Wang J, Cui M, Jiao H, Tong Y, Xu J, Zhao Y, Han M, Liu J. Content analysis of systematic reviews on effectiveness of traditional Chinese medicine. J Tradit Chin Med. 2013;33(2):156-63.

23. Xue CC, Zhang AL, Greenwood KM, Lin V, Story DF. Traditional Chinese medicine: an update on clinical evidence. J Altern Complement Med. 2010;16(3):301-12.

24. Ge B, Zhang Z, Zuo Z. Updates on the clinical evidenced herb-warfarin interactions. eCAM. 2014;2014:957362.

25. Rahal A, Ahmad AH, Kumar A, Mahima, Verma AK, Chakraborty S, Dhama K. Clinical drug interactions: a holistic view. PJBS. 2013;16(16):751-8.

26. Chan TY. The prevalence use and harmful potential of some Chinese herbal medicines in babies and children. Vet Hum Toxicol. 1994:36(3):238-40

27. van Andel T, de Boer HJ, Barnes J, Vandebroek I. Medicinal plants used for menstrual disorders in Latin America, the Caribbean, sub-Saharan Africa, South and Southeast Asia and their uterine properties: a review. J Ethnopharmacol. 2014:155:992.

\section{Submit your next manuscript to BioMed Central and we will help you at every step:}

- We accept pre-submission inquiries

- Our selector tool helps you to find the most relevant journal

- We provide round the clock customer support

- Convenient online submission

- Thorough peer review

- Inclusion in PubMed and all major indexing services

- Maximum visibility for your research

Submit your manuscript at www.biomedcentral.com/submit
O) BioMed Central 